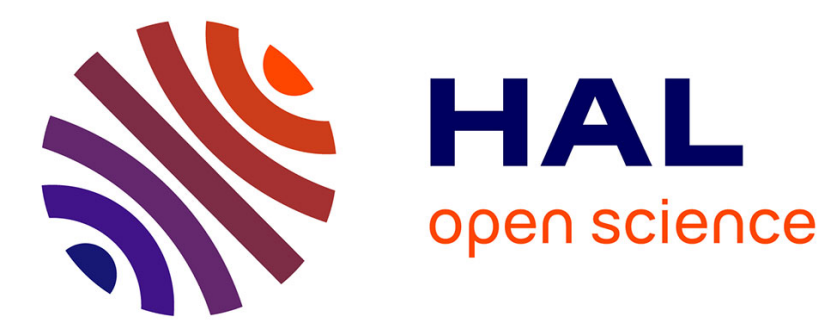

\title{
X-RAY DIFFRACTION STUDY ON LIQUID AND NON CRYSTALLINE SOLID GALLIUM, BISMUTH AND MERCURY
}

A. Bererhi, A. Bizid, Louis Bosio, Robert Cortès, André Defrain, C. Segaud

\section{To cite this version:}

A. Bererhi, A. Bizid, Louis Bosio, Robert Cortès, André Defrain, et al.. X-RAY DIFFRACTION STUDY ON LIQUID AND NON CRYSTALLINE SOLID GALLIUM, BISMUTH AND MERCURY. Journal de Physique Colloques, 1980, 41 (C8), pp.C8-218-C8-221. 10.1051/jphyscol:1980856 . jpa00220363

\section{HAL Id: jpa-00220363 https://hal.science/jpa-00220363}

Submitted on 1 Jan 1980

HAL is a multi-disciplinary open access archive for the deposit and dissemination of scientific research documents, whether they are published or not. The documents may come from teaching and research institutions in France or abroad, or from public or private research centers.
L'archive ouverte pluridisciplinaire HAL, est destinée au dépôt et à la diffusion de documents scientifiques de niveau recherche, publiés ou non, émanant des établissements d'enseignement et de recherche français ou étrangers, des laboratoires publics ou privés. 


\title{
X-RAY DIFFRACTION STUDY ON LIQUID AND NON CRYSTALLINE SOLID EALLIUM, BISMUTH AND MERCURY
}

\author{
A. Bererhi, A. Bizid", L. Bosio, R. Cortes, A. Defrain and C. Segaud \\ Groupe de Recherche $n^{\circ} 4$ du CNRS "Physique des Liquides et Electrochimie", associé à \\ l'Universite Pierre et Marie Curie, 4 place Jussieu, 75230 Paris Cédex 05, France. \\ *Université de Tunis, Faculté des Sciences, Département de Physique, Compus Universitaire \\ 1006 Le Belvédère, Tunis, Tunisie.
}

\begin{abstract}
An attempt is made to compare the structures deduced from X-ray measurements on some pure metals, both in the liquid and the non crystalline state. With $\mathrm{Ga}$ and $\mathrm{Bi}$, the liquid and the amorphous solid structures show some similarities and seem to be correlated with the solid phase which occurs when crystallisation takes place. Different behaviour is found with Hg : the liquid structure factor differs from the structure factor in the amorphous state whose main peak is symmetric in form.
\end{abstract}

\section{INTRODUCTION}

The properties of most of the liquid metals have been successfully described by a hard sphere description in conjonction with perturbation techniques [1]. Concerning the non crystalline solid state, the dense random packing of hard spheres[2] is apparently a satisfactory approach to modelling atomic arrangements in metallic glasses. However, these descriptions completely fail when crystallisation does not form close packed solids ; in these cases, the liquid structure factor often has a shoulder or a hump on the high-angle side of the principal peak and, in amorphous state, neither the structure factor nor the pair correlation function show the characteristic splitting of the second maximum.

The present paper describes the typical behaviour of three of these metals (namely $\mathrm{Ga}, \mathrm{B} i$ and $\mathrm{Hg}$ ) which offer the experimenters the unique opportunity of investigating by $X$-ray diffraction measurements the structure (i) of the normal and supercooled liquid, (ii) of the amorphous solid prepared by vapour deposition onto substrates cooled at very low temperature.

\section{EXPERIMENTS}

An $X$ rays diffractometer operating in a symmetrical reflection mode has been used to determine the structure of both liquid and amorphous solid metals.

The experimental arrangement for the measurement of the scattered intensities by liquids consisted of a theta-theta diffractometer [3] with a stationary, horizontal sample and a bent lithium fluo- ride monochromator in the diffracted beam. The radiations were $\mathrm{Cu}_{\mathrm{K} \alpha}$ and $\mathrm{MO}_{\mathrm{K} \alpha}$. By dividing the sample into small droplets, it was possible to study the structure of supercooled liquids : for Ga and $\mathrm{Hg}$ the dispersions were prepared by using an ultrasonic generator to disperse the molten metals within ethyl alcohoi saturated with sodium oleate, thus allowing experiments under the normal melting point at supercooling of 140 and $61 \mathrm{~K}$ respectively ; for $\mathrm{B} \mathbf{i}$, the procedure of forming droplets to achieve large supercooling [4] was not convenient for $X$-ray investigation because of extraneous Braggs peaks provided by the oxyde-coated droplets : the dispersions were prepared by shaking the molten $\mathrm{Bi}$ in hexadecanol with some sterols as surfactants, the maximum supercooling was thus limited to $68 \mathrm{~K}$.

In all cases, samples were cooled or heated in a vacuum chamber in which the pressure could be reduced to $10^{-5}$ torr except for $\mathrm{Hg}$ where the chamber was filled with helium [5].

Nominally pure amorphous metals are only available by vapour deposition onto liquid helium cooled substrates [2]: the low temperature condensation apparatus, consisting of an jonic ultra-high vacuum system with an electron gun and a liquid helium cryostat, in conjunction with the $X$-ray diffractometer built on the pumping system, has been described elsewhere [6] ; the only modifications consisted in the use of a post-specimen monochromator and a special device for mercury deposition.

Though they were thin (respectively $3,0.2$ and $0.1 \mu \mathrm{m}$ for $\mathrm{Ga}, \mathrm{Bi}$ and $\mathrm{Hg}$ ) the amorphous films were thick enough for $X$-ray diffraction study. Three 
C8-219
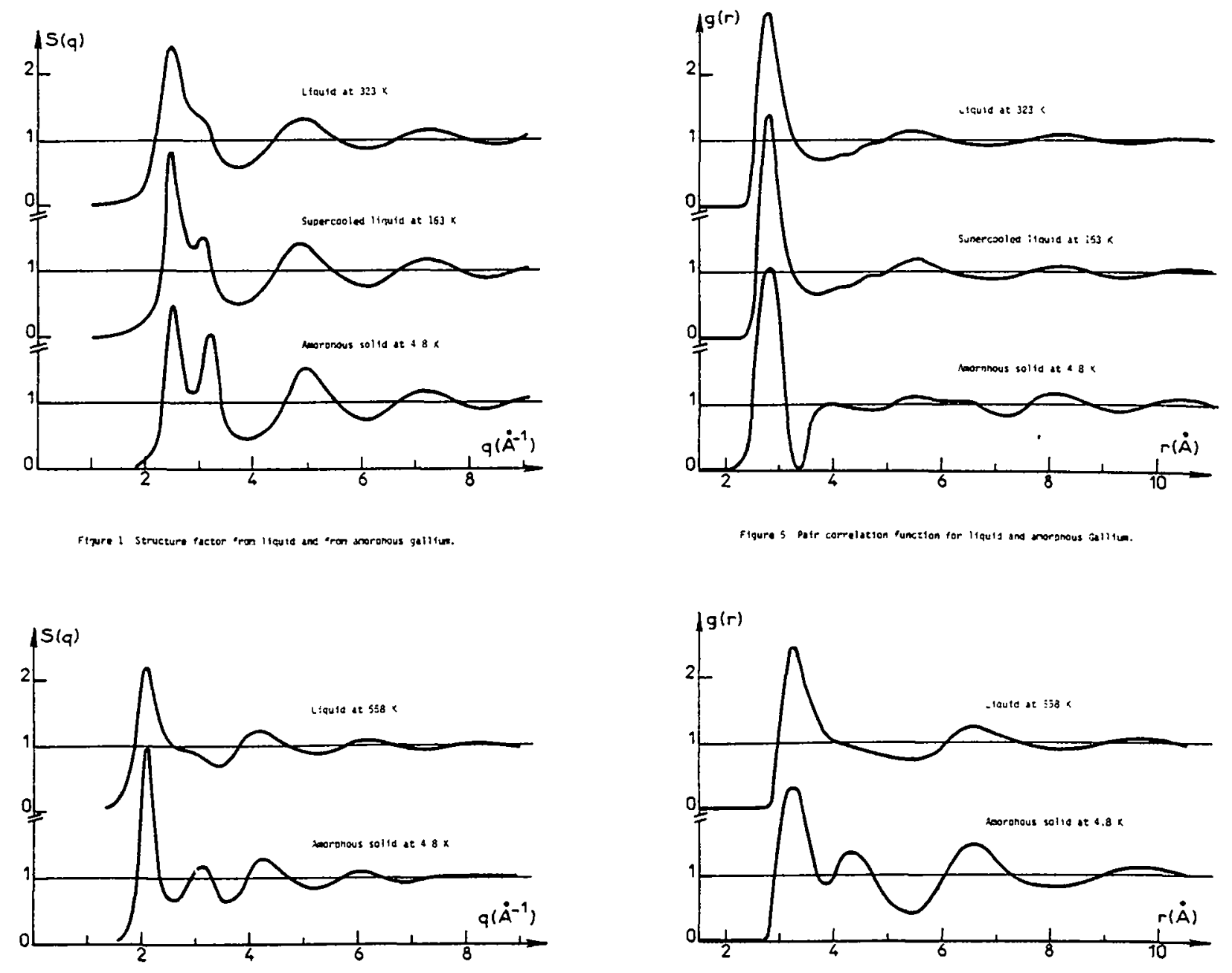

Flgure 2. Structure suctor fron ! lquid sna moromous gignuth

zigures patr correlation function for inula and anornnous 31 smuten
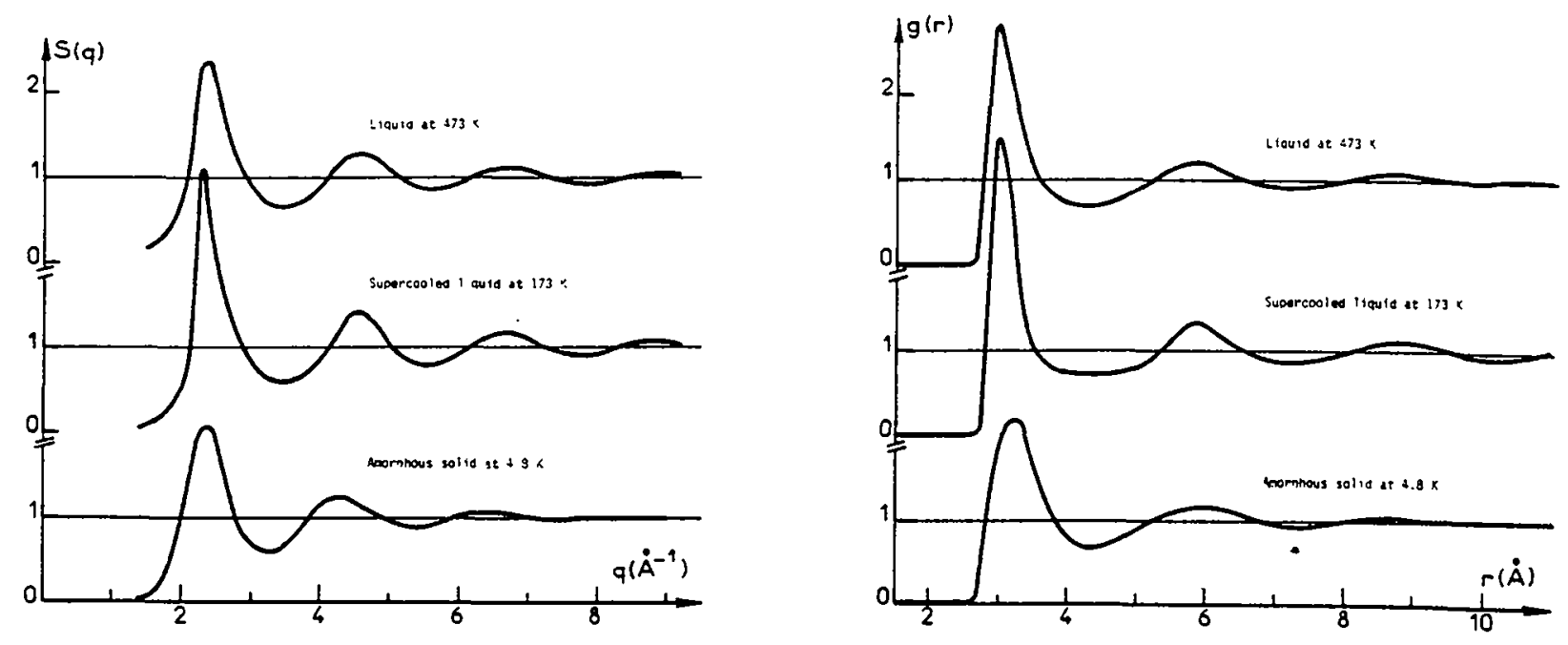

Figure 3. Structure factor fron liquld and anomows sercury

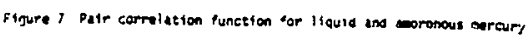


wavelengths were used, $\mathrm{Cr}_{\mathrm{K \alpha}}, \mathrm{Cu}_{\mathrm{K \alpha}}$ and $\mathrm{Mo}_{\mathrm{K \alpha}}$, to obtain reliable data in the low and high wavevector $q=4 \pi \sin \theta / \lambda$ and also to take advantage of the wavelength dependence of X-ray absorption.

\section{RESULTS AND DISCUSSION}

The structure factor $S(q)$ of liquid $\mathrm{Ga}, \mathrm{Bi}$ and $\mathrm{Hg}$ are shown in Fig. 1, 2 and 3. Both Ga and $\mathrm{Bi}$ exhibit a shoulder on the righ-angle side whereas $\mathrm{Hg}$ only shows a hump; in $\mathrm{Ga}$, the shoulder gradually increases when the temperature is lowered but in $\mathrm{Hg}$ and $\mathrm{Bi}$ these anomalies remain unchanged though they are less evident at high temperature because of the broadening of the first maximum. The most noticeable effect of the temperature on the structure factors is the damping in high $q$ range and the reduction of the first peak height $S\left(q_{0}\right)$ as temperature rises; the temperature dependence of $S\left(q_{0}\right)$ is identical for these three metals, as shown in Fig. 4 where the ratio of the height $\left[S\left(q_{0}\right)\right]_{T}$ to that observed at the melting point $\left[S\left(q_{0}\right)\right]_{T m}$ are plotted as a function of the reduced temperature $\mathrm{T} / \mathrm{Tm}$.

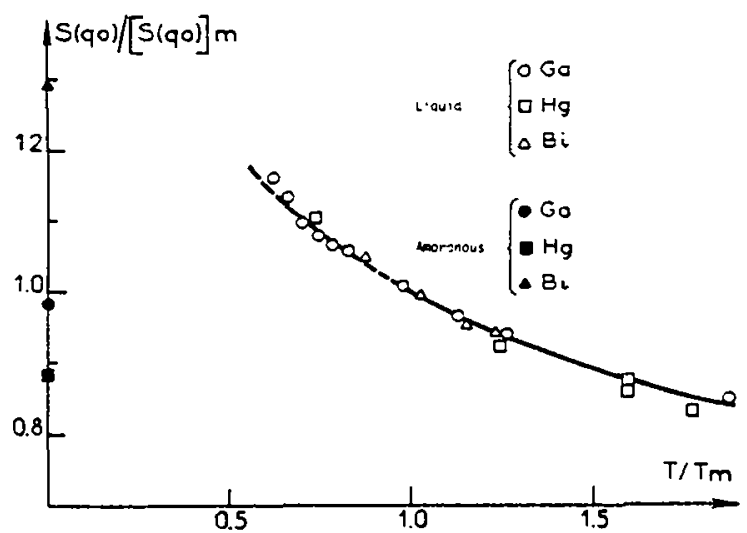

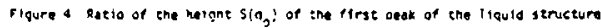

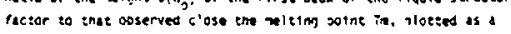

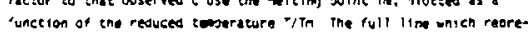

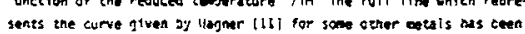
grolongtiod in the sumarcosied seato

From $S(9)$, the pair correlation functions,

$g(r)$ (Fig. 5, 6 and 7), can be obtained in the standard way by Fourier transformation : the structure of liquid $\mathrm{Ga}$ and $\mathrm{Hg}$ remains quite unchanged when the temperature is lowered except some increase in the large range correlation. It is of particular interest to note that experiments on Ga and $\mathrm{Hg}$ have been performed in the strongly supercooled state close to the ultimate stability limit of the liquid state but no striking feature is seen either in $S(q)$ or in $g(r)$ concerning any incipient ordered state as suggested by mean field theory [7]. When freezing occurs in supercooled liquid $\mathrm{Ga}$ it is rather to the metastable $\beta$-phase whereas the normal stable form has always been observed to occur when crystallisation takes place in supercooled liquid $\mathrm{Hg}$ and $\mathrm{Bi}$; moreover, some authors used the crystalline lattice as a framework for describing liquid $\mathrm{Ga}[8], \mathrm{Bi}[9]$ and $\mathrm{Hg}[5,10]$ by a quasi crystalline structure model : they all establish a close correspondence between the liquid and corresponding crystalline solid structure.

The same conclusions may be transposed to the non-crystalline solid $\mathrm{Ga}$ and $\mathrm{Bi}$ : in amorphous state these two metals show evident resemblances to the corresponding liquid both in structure factors (Fig. 1 and 2) and in pair correlation functions (Fig. 5 and 6) ; because of the absence of diffusive displacements in the solid state, the observed oscillations are more pronounced and the shoulders seen in liquids appear better defined.

He think that such a similarity between the liquid and the amorphous structures -supported by the fact that the amorphous films do crystaliize to the same varieties that supercooled liquids-must be connected with the process used to obtain amorphous samples. Indeed, in preparing Ga and $B i$ films by vapour deposition, atoms (or ions) impinge on the cooled substrate with an initial kinetic energy sufficient to disturb the atoms previously deposited and to raise temperature locally up to the melting point ; obviously this effect concerns few atoms around the points of impact and the quench rate is rapid enough to garantee non-crystalline solid formation with some reminiscence of liquid state. Because of the high vapour pressure of mercury it is possible to produce films while the evaporation crucible is maintained at low temperature; atoms reach the substrate without producing too much damage : the structure factor of the amorphous film thus obtained (Fig. 3) exhibit no shoulder on the first peak and rather looks like the hard sphere description and the non-crystalline solid structure of mercury (Fig. 3 and 7 ) notably differs from that in the Tiquid state.

The normalized first peak height of the structure factor obtained from the experiments carried out on the three amorphous metals are shown in Fig. 4 : there is strong evidence that the plots corresponding to the non crystaliine state do not lie on the curve expected from extrapolation of the 
liquid state; it seems probable that this occurrence stems from a more or less relaxed structure in these amorphous films, which suffer no annealing since they are observed to be unstable on heating.

\section{CONCLUSION}

We strove to perform experiments on pure metals since we are concerned with only one kind of atom so that data reduction and structural results are easier to handle. We have no place here either to detail the experimental procedure or to describe the full particularities of the structure deduced from experiments or from modelling. We only emphasized the similarities between the liquid structure and the further crystalline phase in $\mathrm{Ga}, \mathrm{Bi}$ and $\mathrm{Hg}$; in these particular metals, the distorted structure factor whose explanation gave rise to many attempts, has quite identical temperature dependence. In the non crystalline state, $\mathrm{Hg}$ shows a distinct behaviour we attributed to the preparation mode of the amorphous films : it is possible to assume that all non crystalline metals might exhibit a hard sphere structure if, in vapour deposition, atoms reach a cooled substrate with no initial kinetic energy.

\section{REFERENCES}

[1] YOUNG, W. H., Third International Conference on Liquid Metals, Bristol 1976.

[2] CARGILL III, G. S., Solid State Physies 30 Advances in research and application (Academic Press, London 1975).

[3] BIZID, A., BOSIO, L., CORTES, R., DEFRAIN, A., Bull. Soc. Mineral. Cristallog. 100 (1977) 9.

[4] RASMUSSEN, D., LOPER, C., Acta Met. 23 (1975) 1215.

[5] BOSIO,L., CORTES, R., SEGAUD, C., J. Chem.Phys. 71 (1979) 3595 .

[6] BERERHI, A., BOSI0, L., CORTES, R., J. NorCrystalline Solids 30 (1979) 253.

[7] SCHNEIOER, T., BROUT, R., THOMAS, H., FEOER, J., Phys. Rev. Lett. 25 (1970) 1423.

[8] BIZID, A., DEFRAIN, A., BELLISSENT, R., TOURAND, G., J. Phys. 39 (1978) 554.

[9] SEGAUD, C., Ing. Doctorat Paris (1980).

[10] KAPLOW, R., STRONG, S.L., AVERBACH, B.L., Phys. Rev. A138 (1965) 1336.

[11] HAGNER, C.N.J., Third Tnternationa? Conference on Liquid Metals, Bristol 1976. 